\title{
Case report of a young child with disseminated histoplasmosis and review of hyper immunoglobulin e syndrome (HIES)
}

\author{
Wilson S Robinson ${ }^{1,2+}$, Sandra R Arnold ${ }^{1,2+}$, Christie F Michael ${ }^{1,2}$, John D Vickery ${ }^{1}$, Robert A Schoumacher ${ }^{2}$, \\ Eniko K Pivnick ${ }^{2}$, Jewell C Ward ${ }^{2}$, Vijaya Nagabhushanam ${ }^{3}$ and Dukhee B Lew ${ }^{1,2^{*}}$
}

\begin{abstract}
Type 1 hyper IgE syndrome (HIES), also known as Job's Syndrome, is an autosomal dominant disorder due to defects in STAT3 signaling and Th17 differentiation. Symptoms may present during infancy but diagnosis is often made in childhood or later. HIES is characterized by immunologic and non-immunologic findings such as recurrent sinopulmonary infections, recurrent skin infections, multiple fractures, atopic dermatitis and characteristic facies. These manifestations are accompanied by elevated IgE levels and reduced IL-17 producing CD3+CD4+ T cells. Diagnosis in young children can be challenging as symptoms accumulate over time along with confounding clinical dilemmas. A NIH clinical HIES scoring system was developed in 1999, and a more recent scoring system with fewer but more pathogonomonic clinical findings was reported in 2010. These scoring systems can be used as tools to help in grading the likelihood of HIES diagnosis. We report a young child ultimately presenting with disseminated histoplasmosis and a novel STAT3 variant in the SH2 domain.
\end{abstract}

\section{Introduction}

Type 1 hyper IgE syndrome (HIES) is an autosomal dominant disorder due to defects in signal transducer and activator of transcription 3 (STAT3) signaling [1,2]. HIES was first described in 1966 and called Job's syndrome for the clinical manifestation of recurrent staphylococcal abscesses [3]. The association with elevated IgE levels was discovered in 1972 and was referred to as Buckley syndrome [4] which was found to be the same condition as Job's syndrome. The genetic mutation of HIES was discovered in 2007. Minegishi et al. and Holland et al. reported heterozygous dominant-negative mutations in STAT3 in the DNA-binding and SH2 domains [5,6]. STAT3 plays an important signaling role in Th17 differentiation.

Type 1 HIES is characterized by immunologic and non-immunologic findings. These manifestations are accompanied by elevated IgE levels and reduced IL-17 producing $\mathrm{CD} 3+\mathrm{CD} 4+\mathrm{T}$ cells. Immunologic findings

\footnotetext{
* Correspondence: dlew@uthsc.edu

† Contributed equally

'Children's Foundation Research Center at Le Bonheur Children's Hospital,

University of Tennessee Health Center, Memphis, TN 38103-2800, USA

Full list of author information is available at the end of the article
}

include newborn rash, recurrent sinopulmonary infections, recurrent skin infections, recurrent cyst-forming pneumonias, eczema, mucocutaneous fungal disease, eosinophilia and elevated IgE. Non-immunologic findings include characteristic face, retained primary teeth, multiple fractures, scoliosis, hyperextensibility, Chiari I malformations and craniosynostosis.

Diagnosis in young children can be challenging as symptoms accumulate over time along with confounding clinical dilemmas. A clinical HIES scoring system by the National Institutes of Health $(\mathrm{NIH})$ was developed in 1999 [1]. A more recent scoring system with fewer but more pathogonomonic clinical findings was reported in 2010 [2]. These scoring systems can be used as tools to assess the likelihood of HIES diagnosis.

Also reported are autosomal recessive forms of HIES, i.e. defects in dedicator of cytokinesis 8 protein (DOCK8) and tyrosine kinase 2 (TYK2). These forms are less common, mostly described in consanguineous communities and have several different clinical distinctions. 


\section{Case Report}

This patient with wiry hair and square asymmetric face, was initially hospitalized at 5 months of age for pneumonia, multiple fractures, eczema with facial folliculitis but without cold abscess, wheezing, or milk allergy. Evaluation for non-accidental trauma was ongoing. Laboratory findings were as follows: $\operatorname{IgE} 187 \mathrm{IU} / \mathrm{mL}, \operatorname{IgA}<6.3$ $\mathrm{mg} / \mathrm{dL}$, and eosinophil count $3,500 / \mathrm{mm} 3$. IgG, IgM, lymphocyte mitogen stimulation and cell surface markers were normal. Family history was noncontributory. His IgA normalized over the next 2 years. He had nine subsequent hospitalizations due to the following issues: rib fractures and pneumonia, respiratory distress secondary to subglottic cyst, gastroenteritis with dehydration, pneumonia requiring mechanical ventilation, severe dysphagia/aspiration pneumonia requiring G-Tube/Nissen fundoplication, and Streptococcus pneumoniae pneumonia with parapneumonic effusion. He also developed pneumatoceles and required left thoracotomy with bleb plication/pleurodesis. Other pertinent complications included recurrent ear infections and thrush, developmental delay, osteopenia, eczema, cellulitis, and allergic sensitization to egg, cat and dust mites. Further evaluation included normal chromosomes (46XY), CPK, vitamin D, calcium, PTH, and sweat chloride, along with negative HIV screening.

In July 2010, at 33 months of age, he presented with hepatosplenomegaly, hypoxia and respiratory distress. A diffuse opacity was seen on chest xray. Bronchoalveolar lavage showed extracellular and intracellular yeast suspicious for Histoplasma capsulatum. Disseminated histoplasmosis was confirmed by urine and serum antigen levels (both above measurable test limit).

Due to disseminated infection and the complexity of his clinical course, the question of primary immunodeficiency was revisited. His IgE level on initial presentation at 5 months of age was $187 \mathrm{IU} / \mathrm{mL}$, and by 33 months of age had increased to $1,106 \mathrm{IU} / \mathrm{mL}$. The clinical score for HIES progressed to 46 (Table 1). Dihydrorhodamine, Mannan-binding-lectin, $\mathrm{CH} 50$ and mitogen stimulation were normal. Pneumococcal titers were flat despite a history of S. pneumoniae infection and vaccination with 3 out of 4 Prevnar7 doses. Cell surface markers were found to be normal except for slightly elevated activated $\mathrm{T}$ cells at $12 \%$ and slightly decreased $\mathrm{CD} 4+\mathrm{CD} 45+\mathrm{RA}-/$ $\mathrm{RO}+$ memory $\mathrm{T}$ cells at $15 \%$ with normal reference range of $16-46 \%$. Flow cytometric analysis of Th1 and Th17 cells [performed by the Advanced Diagnostic Immunology Laboratories National Jewish Health (Denver, $\mathrm{CO}$ ) as a research development study with a minor modification ( 5 versus 6 hour stimulation) of the method of Ma et al.] [7] revealed low Th17 or IL-17 producing cells $(0.3 \%$ of $\mathrm{CD} 4+\mathrm{T}$ cells; date-matched normal control: $2.1 \%)$. Th17:Th1 ratio was also low
Table 1 Chronologic HIES scoring

\begin{tabular}{|c|c|c|c|c|}
\hline $\begin{array}{l}\text { Age }(\mathrm{mo}) \\
\text { Date }\end{array}$ & $\begin{array}{l}9 \\
\text { June, } \\
2008\end{array}$ & $\begin{array}{l}20 \\
\text { May, } \\
2009\end{array}$ & $\begin{array}{l}23 \\
\text { Aug, } \\
2009\end{array}$ & $\begin{array}{l}33 \\
\text { July, } \\
2010\end{array}$ \\
\hline IgE score (IU/ml) & $1(187)$ & $1(371)$ & $8(1,011)$ & $8(1,106)$ \\
\hline Skin abscess & 0 & 0 & 0 & 2 \\
\hline Pneumonia & 2 & 4 & 6 & 8 \\
\hline Lung anomalies & 0 & 0 & 8 & 8 \\
\hline Fractures & 4 & 4 & 4 & 8 \\
\hline Eczema & 2 & 2 & 2 & 2 \\
\hline URIs/year & 2 & 2 & 2 & 2 \\
\hline Candidiasis & 1 & 1 & 1 & 1 \\
\hline Serious infections & 0 & 0 & 0 & 4 \\
\hline $\begin{array}{l}\text { Young age } \\
\text { correction }\end{array}$ & 7 & 5 & 5 & 3 \\
\hline NIH Score & 19 & 19 & 36 & 46 \\
\hline Pneumonia & N/A & N/A & $6 \times 2.5$ & $8 \times 2.5$ \\
\hline Pathologic fractures & N/A & N/A & $4 \times 3.33$ & $8 \times 3.33$ \\
\hline STAT3 Score & N/A & $\mathrm{N} / \mathrm{A}$ & 28.32 & 46.64 \\
\hline
\end{tabular}

$\mathrm{NIH}$ score: unlikely, < 20; indeterminate, 20-40; suggestive of AD-HIES, $>40$ STAT3 score: possible, $>30+\operatorname{lgE} \geq 1,000 \mathrm{IU} / \mathrm{ml}$, probable: $>30+\operatorname{lgE} \geq 1,000 \mathrm{IU} /$ $\mathrm{ml}+$ low Th17 and/or positive F.Hx; definitive, $>30+\mathrm{lgE} \geq 1,000 \mathrm{IU} / \mathrm{ml}+$ heterozygous STAT3 mutation

(9:1,000). STAT3 gene analysis revealed a missense mutation in exon 20 within the Src-homology (SH2) domain [c.1772A > T, amino acid change p.Lys591Met] (Figure 1).

Informed consent was obtained and approved by UTHSC IRB.

\section{Discussion}

We report a case of disseminated histoplasmosis in a young child with STAT3-HIES [c.1772A > T, amino acid change p.Lys591Met]. Our patient's missense mutation in the SH2 domain has not been previously reported. Woellner et al. identified a missense mutation in the same amino acid [c.1771A > G, amino acid change p.Lys591Glu] but no clinical information is available [2].

\section{Genetics}

AD-HIES is now defined by heterozygous mutation detection in STAT3 which contains 24 exons and 3 splice variants. STAT3 sequencing became commercially available in mid-2009 which provides the opportunity for more expedited and objective diagnosis but must be weighed by the level of clinical suspicion due to healthcare cost burden. Over $95 \%$ of AD-HIES have detectable STAT3 mutations and all domains have had mutations described including the N-terminal, coiled-coil, DNAbinding, linker[8], SH2 and transactivation domains.

Most of these mutations affect either the DNA-binding domain or the $\mathrm{SH} 2$ domain. Genotype-phenotype correlations involving most common domains and 


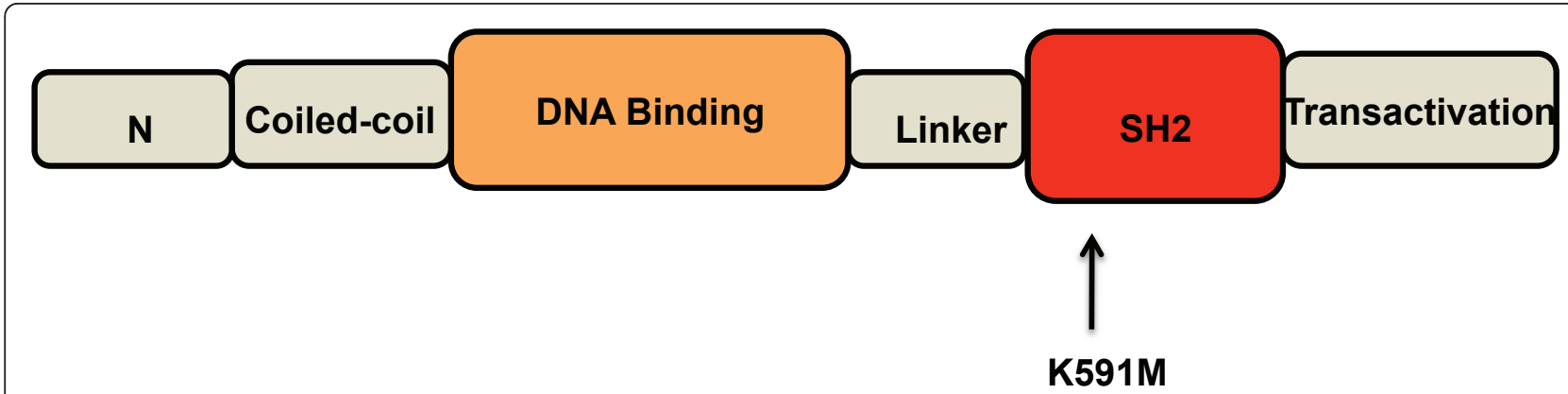

Figure 1 STAT3 Novel Variant. Our patient's mutation on a schematic primary structure of STAT3 gene. STAT3 analysis revealed a missense mutation in exon 20 within the SH2 domain [c.1772A > T, amino acid change p.Lys591Met].

hotspots within these regions have been investigated [9]. Sixty-five subjects (35 with DNA-binding domain mutation and 30 with $\mathrm{SH} 2$ domain mutation) were evaluated and suggest increased non-immunologic features in the $\mathrm{SH} 2$ domain group including high palate, increased interalar distance as well as increased scoliosis in a younger patient subset. They also showed a possible association with increased mortality risk secondary to infection as 6 of the 7 infection related deaths had DNA-binding domain mutations (five in the arginine 382 hotspot). Causative organisms were not reported but a trend of increased Varicella-Zoster reactivation was observed [9]. Although these findings are suggestive, this sample size still lacks statistical power which has been true in other studies as well $[10,11]$. Our patient has a mutation in SH2 domain and does not have the aforementioned non-immunologic findings, but over time they could develop.

\section{Role in infection}

Disseminated histoplasmosis in HIES is rare and not yet reported in young children. We found six case-reports total (5 patients) in the literature of histoplasma infection in HIES. Three had gastrointestinal tract disease (two teenagers and one adult) [12]. One patient had laryngeal histoplasma only [11]. The other case, reported twice, involves an adult male with budding yeast from a tongue ulcer and histoplasma cultured from right middle lobe infiltrate $[11,13]$. Invasive fungal disease in HIES is typically seen in adults and attributed to lung damage from previous bacterial pneumonias [11]. Our patient developed pneumatoceles following pneumococcal pneumonia that possibly served as a nidus for Histoplasma, which ultimately disseminated. There are reports of other invasive mycotic diseases [14]. These cases suggest increased risk of disseminated fungal infection with endemic mycoses in HIES patients, raising the possibility that STAT3 has a role in intracellular infection.

Fungal pathogens are recognized by C-type lectin receptors (Dectin-1, Dectin-2, macrophage-inducible C- type lectin, mannose receptor), and there are recent reports indicating variants of either these receptors or down-stream signaling molecules will result in defective NFkB function. NFkB normally promotes IL1 $\beta$, IL-6 and IL-23 cytokine production by macrophages [15]. These macrophage cytokines facilitate STAT3 dependent Th17 cell differentiation. Th17 cells produce cytokines (i.e. IL17, IL-21, IL-22) crucial for host defense against bacteria and fungi [15]. Thus if STAT3 signaling is defective, as in HIES, Th17 differentiation is suppressed and there is resultant susceptibility to opportunistic infection [15].

HIES and chronic mucocutaneous disease (CMCD) share the clinical similarities of recurrent staphylococcal and candidal skin infections resulting from defective Th17 T cells. IL-17A and IL-17F are members of the IL-17 family that seem to play an important role in prevention of these infections. It has been recently reported that deficits in IL-17 production result in defective salivary activity due to antimicrobial protein impairment suggested to play a major role in initial fungal defense [16]. In addition, IL-22 stimulation results in bolstering the innate response through its production of $\beta$-defensins. Recently described autosomal recessive defect in IL-17 receptor A (IL-17RA) and autosomal dominant defect in IL-17F are both associated with increased staphylococcal and candidal infections [17]. In HIES, "cold boils" and recurrent pulmonary infections by Staphylococcus aureus or Haemophilus influenza are common.

A commonly described opportunistic fungal infection in primary immunodeficiency is Pneumocystis jiroveci although it is more often described in T-cell immunodeficiences. $P$ jiroveci (formerly $P$ carinii) is an extracellular fungus that has been described in several patients with HIES. Holland et al report seven HIES, HIV-negative patients with $P$ jiroveci found in respiratory or pulmonary specimens [18]. Those patients still living responded to appropriate therapy and were not continued on prophylaxis. Whether $P$ jiroveci susceptibility in HIES is due to preceding chronic lung disease or immunologic abnormalities is not known. The IL-23-IL-17 
cytokine axis is important in the murine model via IL23 leading to increased production of IL-17 and IL-22 $[19,20]$. Our patient did have BAL findings of extracellular yeast and thus was treated with three weeks of Bactrim, but he never had a definitive diagnosis of $P$ jirovec $i$ pneumonia.

\section{Scoring systems}

As previously mentioned over 30 patients with HIES were used to develop a clinical scoring system in 1999 (NIH-HIES score) [1]. A more recent scoring system (referred to as the HIES STAT3 score) published in February 2010 attempted to define clinical features that were better predicators of genotype [2]. The authors studied over 100 patients with presumed HIES and IgE levels $>1,000 \mathrm{IU} / \mathrm{mL}$ to determine the five features that comprise their criteria: pneumonia, newborn rash, pathologic fractures, characteristic face of Job's syndrome and cathedral palate [2]. The terminology used is more consistent with immunodeficiency diagnostic criteria of other more studied diseases.

The newer scoring system also utilizes Th17 cell counts in its diagnostic guidelines. Multiple groups have shown reduced Th17 cell counts expressed as percentage of CD4+ T cells in HIES $[2,10,21,22]$. This test is not currently commercially available, but has been shown helpful in differentiating between HIES versus atopic dermatitis [22].

Our patient's clinical scoring was recorded over time and increased with sequential calculations. This trend exemplifies how patients accrue symptoms over time making early diagnosis in young children very difficult.

\section{Confounders}

Defects in STAT3 signaling and its pathobiologic implications on immunologic and non-immunologic pathways will not completely manifest upon initial presentation. Development of additional symptoms over time is the expectation in HIES. For this reason, the NIH scoring system has a young age correction since certain parameters (i.e. multiple pneumonias, retention of primary teeth, scoliosis) will not be present until later in life. Young children can often have additional confounding co-morbidities that lead to unnecessary evaluations and delay in diagnosis.

Our patient's symptoms could be attributed to other possible etiologies. He had multiple rib fractures at different stages of healing that were suspicious for nonaccidental trauma. With his osteopenia, he was predisposed to increased risk for fractures. Additionally, his multiple inhalant and food allergies could have contributed to eosinophilia and elevated IgE levels. Multiple pneumonias in children with gastroesophageal reflux are common due to aspiration. Our patient had severe reflux that required G-tube and Nissen fundoplication. As he was a late premature infant with a transiently low IgA level, increased risk for infection was expected. Both IgA and IL-17 responses are important in defense against fungi [23]. Moreover, B cell immunoglobulin production and Th17 cells can be primed by Dectin-1 [24], although we have not investigated the Dectin-1 response in our patient.

There are many pediatric diagnoses much more common than HIES that could explain the aspects of our patient's presentation. Therefore, like our patient, young children are more prone to have a delay in diagnosis, whereas older children and adults will have accumulated more hallmark symptoms. The total IgE level can trend down to under $1,000 \mathrm{IU} / \mathrm{mL}$, although values do not correlate well with disease activity or severity. Thus, clinical suspicion, coupled with scoring systems repeated over time can facilitate ultimate diagnosis.

\section{Management}

As with most primary immunodeficiences without a cure, AD-HIES management focuses on preventative measures to limit the number and severity of infections. Our patient will remain on indefinite prophylactic antibiotic and antifungal therapy. Although he initially responded to booster with Prevnar 13, his immunity waned over 9 months to only one protective titer. Institution of prophylactic antibiotics targeted against pyogenic bacteria (namely Staphylococcus aureus) is paramount. Second-generation cephalosporins or trimethoprim/sulfamethoxazole are options for antibacterial prophylaxis; however, if lungs have structural damage, antimicrobial coverage is broadened to include Pseudomonas. History of fungal infection requires prophylactic treatment with fluconazole or itraconazole. Aggressive treatment at the earliest sign of infection is necessary to prevent serious illness. As these patients may have only mild symptoms due to impairment of acute phase cytokines (i.e. IL-6), symptoms may not correlate with severity of disease. As previously reported, routine PJP prophylaxis does not appear to be necessary [6]. For patients with poor antibody production, IVIG can be considered. There are several case reports finding benefit in using IVIG for acute infection or prophylaxis, but no controlled studies exist at this time.

In addition to defects in the immune system, there are also non-immunologic disease manifestations that must be managed. Skin care focuses on reduction of bacterial colonization on the skin. Frequent bleach baths followed by moisturizing and adequate control of pruritus are recommended. Optimizing vitamin $\mathrm{D}$ and calcium intake is helpful for those patients with osteopenia. A predilection towards aneurysms makes blood pressure control important. Evaluation for retention of primary 
Table 2 Clinical and management features of different forms of HIES

\begin{tabular}{|c|c|c|c|c|}
\hline Mutation & Inheritance & $\begin{array}{l}\text { Cases } \\
\text { reported }\end{array}$ & Clinical distinctive characteristics & Management \\
\hline STAT3 & $A D$ & $\begin{array}{l}300-400 \text { (in } U \text {. } \\
\text { S.); } 0.5-1 \text { per } \\
\text { million }\end{array}$ & Skeletal and dental abnormalities & $\begin{array}{l}\text { Non-immunologic evaluation and treatment, prophylactic } \\
\text { antibiotics }+/ \text { - antifungals }\end{array}$ \\
\hline TYK2 & $A R$ & $\begin{array}{l}1-2 \text { (none in } \\
\text { U.S.) }\end{array}$ & $\begin{array}{l}\text { No pneumatoceles, recurrent viral infections, } \\
\text { mycobacterial infection }\end{array}$ & Prophylactic antibiotics $+/$ - antifungals $+/$ - antivirals \\
\hline DOC8 & $A R$ & $50-60$ & $\begin{array}{l}\text { Recurrent viral infections, food allergies/ } \\
\text { rhinitis, Iymphopenia, increased risk of } \\
\text { malignancy, CNS vasculitis }\end{array}$ & $\begin{array}{l}\text { Prophylactic antibiotics and antivirals }+/ \text { - antifungals, IVIG } \\
\text { if antibody deficiency, allogeneic hematopoietic stem cell } \\
\text { transplantation }\end{array}$ \\
\hline
\end{tabular}

teeth and scoliosis in childhood is necessary. There should also be monitoring for signs and symptoms of lymphoma due to the increased incidence in AD-HIES. These patients have a chronic disease that can result in generalized or specific pain, depression, anxiety and fatigue. If chronic symptoms are affecting quality of life, then complementary medicine such as acupuncture can be attempted [25].

Hematopoietic stem cell transplant (HSCT) is generally ineffective in type 1 HIES [26,27]. More recently, however, myeloablative allogeneic HSCT proved effective in two unrelated boys with AD-HIES and nonHodgkin's lymphoma who continue to have normal immune reconstitution and no progression of nonimmunologic manifestations at follow-up 10 and 14 years [28].

\section{Autosomal recessive forms}

In addition to the autosomal dominant inheritance patterns of HIES there are less prevalent forms of autosomal recessive inheritance (Table 2). Tyrosine kinase 2 (TYK2) defect was discovered in 2006 and dedicator of cytokinesis 8 protein (DOCK8) defect in 2009 [29,30]. These autosomal recessive forms share some of the immunologic manifestations of AD-HIES but do not have the same nonimmunologic findings. TYK2-HIES has been described in one patient and DOCK8-HIES has been described in < 100 patients to date. They both have recurrent cutaneous and pulmonary bacterial and fungal infections, eczema, eosinophilia and elevated IgE. TYK2-HIES does not have development of pneumatoceles and both forms are distinct given their susceptibility to viral infections such as herpes and molluscum contagiosum [31]. Both forms are also prone to allergic rhinitis and food allergies whereas this finding is atypical in AD-HIES. DOCK8-HIES is also associated with susceptibility to Salmonella and Giardia infections as well as development of early onset malignancies and central nervous system vasculitis [31]. These patients have a poor prognosis. Stem cell transplant has been successful in DOCK8-HIES [32-34].

Our patient and another patient previously reported by our group [35] were found to have significant inhalant and food sensitivity which is uncommon in AD-HIES. The previously reported case had IgE sensitization proven by skin and serum testing as well as clinical correlation by double-blind, placebo-controlled challenge to cow's milk. In both cases avoidance of milk protein and usage of elemental formula was an effective treatment.

\section{Conclusions}

This case underscores the inherent diagnostic difficulty of HIES in young children with confounding co-morbidities (food and inhalant allergies which are unusual features for STAT3-HIES, transiently low IgA, aspiration pneumonia, etc.). Clinical scoring systems establish threshold scores for HIES suspicion: 40 and 30+IgE > $1,000 \mathrm{IU} / \mathrm{ml}$, in the NIH-HIES and HIES STAT3 systems, respectively $[1,2]$. Utilizing clinical scoring systems and maintaining an appropriate level of suspicion, clinicians can determine when STAT3 mutation analysis is necessary. Availability of peripheral blood Th17 cell enumeration at a clinical diagnostic laboratory would allow for more expedient diagnosis and help to distinguish HIES from other diseases with elevated IgE, namely atopic dermatitis [22]. Prophylactic therapy with antibacterial and antifungal agents (when indicated) are key points in patient management, along with regular monitoring of vaccine titers and proactive vaccination. This case of STAT3-HIES also highlights the inherent susceptibility of these patients to intracellular organisms endemic to the region (in our case, histoplasmosis). The clinical course and outcome for our patient may be instructive for other physicians managing patients with STAT3-HIES.

\section{Acknowledgements}

Authors thank Mr. Benjamin Efaw ${ }^{3}$ for his technical assistance in Th17 cell analysis and Drs. Russell W. Chesney and Karen L. Lakin for their clinical assistance.

\section{Author details}

${ }^{1}$ Children's Foundation Research Center at Le Bonheur Children's Hospital, University of Tennessee Health Center, Memphis, TN 38103-2800, USA.

${ }^{2}$ Department of Pediatrics, University of Tennessee Health Science Center, 
Memphis, TN 38103, USA. ${ }^{3}$ Advanced Diagnostics Immunology Laboratories, National Jewish Hospital, Denver, CO 80015, USA.

\section{Authors' contributions}

WSR contributed to literature search relevant to STAT3, interpretation of the results, and wrote the first draft of this report. SRA contributed to the diagnostic procedures for disseminated histoplasmosis, formulated treatment and prevention regimen, wrote the relevant section, and critically revised the report. CFM contributed to overall diagnostic procedures and management, and critical revision of the report. JDV carefully assessed HIES scores (Table 1), contributed to literature search, the section pertaining to the Th17 cell and fungal infection pathogenesis aspect. RAS contributed to the critical diagnostic procedures for disseminated histoplasmosis and immune deficiency, formulated treatment regimen, and critically revised the manuscript. EKP contributed to genetic evaluation and interpretation of the STAT3 variant results, and critical manuscript revision. JCW contributed to genetic evaluation, interpretation of the STAT3 variant results, and critical manuscript revision. VN conducted Th17 cell analysis. DBL directed overall diagnostic priorities and management, contributed to literature search and manuscript preparation. All authors read and approved the final manuscript.

\section{Competing interests}

The authors declare that they have no competing interests.

Received: 21 September 2011 Accepted: 29 November 2011 Published: 29 November 2011

\section{References}

1. Grimbacher B, Schäffer AA, Holland SM, Davis J, Gallin JI, Malech HL, et al: Genetic linkage of hyper-IgE syndrome to chromosome 4. Am J Hum Genet 1999, 65:735-44.

2. Woellner C, Gertz EM, Schaffer AA, Lagos M, Perro M, Glocker EO, et al: Mutations in STAT3 and diagnostic guidelines for hyper-IgE syndrome. J Allergy Clin Immunol 2010, 125:424-32.

3. Davis SD, Schaller J, Wedgewood RJ: Job's syndrome. Recurrent, "cold," staphylococcal abscesses. Lancet 1966, 1:1013-15.

4. Buckley RH, Wray BB, Belmaker EZ: Extreme hyperimmunglobulin E and undue susceptibility to infection. Pediatrics 1972, 49:59-70.

5. Minegishi $Y$, Saito M, Tsuchiya S, Tsuge I, Takada H, Hara T, Kawamura N, Ariga T, Pasic S, Stojkovic O, Metin A, Karasuyama H: Dominant-negative mutations in the DNA-binding domain of STAT3 cause hyper-lgE syndrome. Nature 2007, 448:1058-62.

6. Holland SM, DeLeo FR, Elloumi HZ, Hsu AP, Uzel G, Brodsky N, Freeman AF, Demidowich A, Davis J, Turner ML, Anderson VL, Darnell DN, Welch PA, Kuhns DB, Frucht DM, Malech HL, Gallin JI, Kobayashi SD, Whitney AR, Voyich JM, Musser JM, Woellner C, Schäffer AA, Puck JM, Grimbacher B: STAT3 mutations in the hyper-lgE syndrome. N Eng J Med 2007, 357:1608-19.

7. Ma CS, Chew GY, Simpson N, Priyadarshi A, Wong M, Grimbacher B, et al: Deficiency of Th17 cells in hyper IgE syndrome due to mutations in STAT3. J Exp Med 2008, 205(7):1551-57.

8. Kim H-J, Kim J-H, Shin YK, Lee S-I, Ahn K-M: A novel mutation in the linker domain of thesignal transducer and activator of transcription 3 gene, $\mathrm{p}$. Lys531Glu, in hyper-IgE syndrome. J Allergy Clin Immuonol 2009, 123:956-58.

9. Heimall J, Davis J, Shaw PA, Hsu AP, Gu W, Welch P, et al: Paucity of genotype-phenotype correlations in STAT3 mutation positive Hyper IgE Syndrome (HIES). Clin Immunol 2011, 139(1):75-84.

10. Renner ED, Rylaarsdam S, Aňover-Sombke S, Rack AL, Reichenbach J, Carey JC, Zhu Q, Jansson AF, Barboza J, Schimke LF, Leppert MF, Getz MM, Seger RA, Hill HR, Belohradsky BH, Torgerson TR, Ochs HD: Novel signal transducer and activator of transcription 3 (STAT3) mutations, reduced TH17 cell numbers, and variably defective STAT3 phosphorylation in hyper-IgE syndrome. J Allergy Clin Immuonol 2008, 122:181-87.

11. Vinh DC, Sugui JA, Hsu AP, Freeman AF, Holland SM: Invasive fungal disease in autosomal-dominant hyper-lgE syndrome. J Allergy Clin Immunol 2010, 125:1389-90.

12. Steiner SJ, Kleiman MB, Corkins MR, Christenon JC, Wheat LJ: lleocecal histoplasmosis simulating Crohn disease in a patient with hyperimmunoglobulin E syndrome. Pediatr Infect Dis J 2009, 28:744-46.
13. Desai K, Huston DP, Harriman GR: Previously undiagnosed hyper-IgE syndrome in an adult with multiple systemic fungal infections. $J$ Allergy Clin Immunol 1996, 98:1123-24.

14. Powers AE, Bender JM, Kuma'novics A, Ampofo K, Augustine N, Pavia AT, et al: Coccidiodes immitis meningitis in a patient with hyperimmunoglobulin $\mathrm{E}$ syndrome due to a novel mutation in a signal transducer and activator of transcription. Pediatr Infect Dis J 2009, 28:664-66

15. Vautier S, de Sousa M, Brown G: C-type lectins, fungi and Th17 responses. Cytokine \& Growth Factor Reviews 2010, 21:405-12.

16. Conti HR, Baker O, Freeman AF, Jang WS, Holland SM, Li RA, Edgerton M, Gaffen SL: New mechanism of oral immunity to mucosal candidiasis in hyper-IgE syndrome. Mucosal Immunology 2011.

17. Puel A, Cypowyj S, Bustamante J, Wright JF, Liu L, Lim HK, Migaud M, Israel L, Chrabieh M, Audry M, Gumbleton M, Toulon A, Bodemer C, ElBaghdadi J, Whitters M, Paradis T, Brooks J, Collins M, Wolfman NM, AlMuhsen S, Galicchio M, Abel L, Picard Capucine, Casanova JL: Chronic mucocutaneous candidiasis in humans with inborn errors of interleukin17 immunity. Science 2011, 332:65-68.

18. Freeman AF, Davis J, Anderson VL, Barson W, Darnell DN, Puck JM, Holland SM: Pneumocystis jiroveci infection in patients with hyper-lgE syndrome. Pediatrics 2006, 118:e1271-75.

19. Rudner XL, Happel KI, Young EA, Shellito JE: Interleukin-23 (IL-23)-IL-17 cytokine axis in murine Pneumocystis carinii infection. Infection and Immunity 2007, 75:3055-61.

20. Shellito JE, Rudner $X$, Ruan S: Role of interleukin-23 in host defense against Pneumocystis carinii infection. Am J Respir Crit Care Med 2010, 181:A5119.

21. Milner JD, Brenchley JM, Laurence A, Freeman AF, Hill BJ, Elias KM, Kanno Y, Spalding C, Elloumi HZ, Paulson ML, Davis J, Hsu A, Asher Al, O'Shea J, Holland SM, Paul WE, Douek DC: Impaired TH17 cell differentiation in subjects with autosomal dominant hyper-lgE syndrome. Nature 2008, 452:773-77.

22. Schimke L, Sawalle-Belohradsky J, Roesler J, Wollenberg A, Rack A, Borte M, et al: Diagnostic approach to the hyper-IgE syndromes: Immunologic and clinical key findings to differentiate hyper-IgE syndromes from atopic dermatitis. J Allergy Clin Immunol 2010, 126:611-17.

23. van Spriel AB, Sofi M, Gartlan KH, van der Schaaf A, Verschueren I, Torensma R, Raymakers RA, Loveland BE, Netea MG, Adema GJ, Wright MD, Figdor CG: The tetraspanin protein CD37 regulates IgA responses and anti-fungal immunity. PLoS Pathog 2009, 5(3):e1000338, Epub 2009 Mar 13.

24. Agrawal S, Gupta S, Agrawal A: Human dendritic cells activated via dectin-1 are efficient at priming Th17, cytotoxic CD8 T and B cell responses. PLoS One 2010, 5(10):e13418.

25. Ge AX, Ryan ME, Holland SM, Freeman AF, Anderson VL, Wang F, Fleshman JW: Acupuncture for symptom management in patients with hyper-IgE (Job's) syndrome. J Alternative \& Complementary Med 2011, 17(1):71-76.

26. Nester TA, Wagnon AH, Reilly WF, Spitzer G, Kjeldsberg CR, Hill HR: Effects of allogeneic peripheral stem cell transplantation in a patient with Job's syndrome of hyperimmunoglobulinemia $\mathrm{E}$ and recurrent infections. Am J Med 1998, 108:162-4.

27. Gennery AR, Flood TJ, Abinun M, Cant AJ: Bone marrow transplantation does not correct the hyper IgE syndrome. Bone Marrow Transplant 2000, 25:1303-5.

28. Goussetis E, Peristeri I, Kitra V, Traeger-Synodinos J, Theodosaki M, Psarra K, Kanariou M, Tzortzatou-Stathopoulou F, Petrakou E, Fylaktou I, Kanavakis E, Graphakos : Successful long-term immunologic reconstitution by allogeneic hematopoietic stem cell transplantation cures patients with autosomal dominant hyper-IgE syndrome. J Allergy Clin Immunol 2010, 126:392-94.

29. Minegishi Y, Saito M, Morio T, Watanabe K, Agematsu K, Tsuchiya S, Takada H, Hara T, Kawamura N, Ariga T, Kaneko H, Kondo N, Tsuge I, Yachie A, Sakiyama Y, Iwata T, Bessho F, Ohishi T, Joh K, Imai K, Kogawa K, Shinohara M, Fujieda M, Wakiguchi H, Pasic S, Abinum M, Nonoyama S, Karasuyama H: Human tyrosine kinase 2 deficiency reveals its requisite roles in multiple cytokine signals involved in innate and acquired immunity. Immunity 2006, 25:745-55.

30. Zhang $Q$, Davis JC, Lamborn IT, Freeman AF, Jing H, Favreau AJ, Matthews HF, Davis J, Turner ML, Uzel G, Holland SM, Su HC: Combined 
immunodeficiency associated with DOCK8 mutations. New Eng J of Med 2009, 361:2046-55.

31. Su H: Dedicator of cyokinesis 8 (DOCK8) deficiency. Curr Opin All \& Clin Imm 2010, 10:515-20.

32. Bittner TC, Pannicke U, Renner ED, Notheis G, Hoffman F, Belohradsky BH, Wintergerst U, Hauser M, Klein B, Schwarz K, Schmid I, Albert MH: Successful long-term correction of autosomal recessive hyper-IgE syndrome due to DOCK8 deficiency by hematopoietic stem cell transplantation. Klin Padiatr 2010, 222:351-5.

33. McDonald DR, Massaad MJ, Johnston A, Keles S, Chatila T, Geha RS, Pai SY: Successful engraftment of donor marrow after allogeneic hematopoietic cell transplantation in autosomal-recessive hyper-lgE syndrome caused by dedicator of cytokinesis 8 deficiency. J Allergy Clin Immunol 2010, 126:1304-5.

34. Barlogis V, Galambrun C, Chambost H, Lamoureux-Toth S, Petit P, Stephan JL, Michel G, Fischer A, Picard C: Successful allogeneic hematopoietic stem cell transplantation for DOCK8 deficiency. J Allergy Clin Immunol 2011, [Epub].

35. Hernandez-Trujillo VP, Nguyen WT, Belleau JT, Jeng M, Conley ME, Lew DB: Cow's milk allergy in a patient with hyper-IgE syndrome. Ann Allergy Asthma Immunol 2004, 92(4):469-74.

doi:10.1186/1476-7961-9-14

Cite this article as: Robinson et al: Case report of a young child with disseminated histoplasmosis and review of hyper immunoglobulin e syndrome (HIES). Clinical and Molecular Allergy 2011 9:14.

\section{Submit your next manuscript to BioMed Central} and take full advantage of:

- Convenient online submission

- Thorough peer review

- No space constraints or color figure charges

- Immediate publication on acceptance

- Inclusion in PubMed, CAS, Scopus and Google Scholar

- Research which is freely available for redistribution

Submit your manuscript at www.biomedcentral.com/submit 